\title{
Produtividade e composição bromatológica de Panicum maximum cv. Mombaça sob irrigação e adubação azotada
} Yield of Mombaça grass under irrigation and nitrogen fertilization

\author{
William de J. E. Mochel Filho ${ }^{1}$ Maria S. de S. Carneiro ${ }^{1}$, Alex C. Andrade², Elzânia S. Pereira ${ }^{1}$, \\ Albericio P. de Andrade ${ }^{3}$, Magno J. da D. S. Cândido', João A. Magalhães4,*, Braz H. N. \\ Rodrigues ${ }^{4}$, Francisco J. de S. Santos ${ }^{4}$ e Newton de L. Costa 5 \\ 1 Universidade Federal do Ceará, Departamento de Zootecnia/Programa de Pós-Graduação em Zootecnia. Av. Mister Hull, 2977. Caixa-postal: 12168. CEP 60021-970. Fortaleza, Ceará, Brasil; \\ 2 Universidade Estadual do Piauí, Av. Nossa Sra. de Fátima, s/n. Parnaíba, Piauí, Brasil. CEP: 64002-150, Brasil; \\ 3 Universidade Federal da Paraíba. CEP 58397-000. Areia, Paraíba, Brasil; \\ 4 Empresa Brasileira de Pesquisa Agropecuária - Embrapa/Centro de Pesquisa Agropecuária do Meio-Norte, CPAMN. Br 343, km 35. Caixa Postal 341. Parnaíba, Piauí, CEP 64200-97 Brasil; \\ ${ }_{5}^{5}$ Empresa Brasileira de Pesquisa Agropecuária - Embrapa/Centro de Pesquisa Agroflorestal de Roraima, CPAFRR. Boa Vista, Roraima. CEP: 69301-970, Brasil. \\ (*E-mail:joão.magalhaes@embrapa.br) \\ http://dx.doi.org/10.19084/RCA14154
}

Recebido/received: 2014.11 .12

Recebido em versão revista/received in revised form: 2015.07.07

Aceite/accepted: 2015.07 .08

\section{R e s u mo}

Foram avaliados os efeitos de diferentes lâminas de irrigação e doses de azoto $(\mathrm{N})$ sobre a produtividade, eficiência do uso do azoto (EUN) e composição bromatológica do Panicum maximum cv. Mombaça. O delineamento experimental foi em blocos casualizados, em esquema fatorial 2x4, com três repetições, sendo dois níveis de irrigação (50\% e $80 \%$ da evaporação do Tanque Classe "A", ECA) e quatro doses de N (200, 400, 600 e 800 kg/ha/ano). As lâminas de irrigação aplicadas apresentaram comportamentos semelhantes em relação à EUN, produção de matéria seca total (PMST), de folhas (PMSF) e colmos (PMSC), e teores de fibra em detergente neutro (FDN). A adubação azotada influenciou positivamente a PMST, PMSF e PMSC, no entanto, diminuiu a EUN. Os teores de proteína bruta (PB) das folhas e colmos foram influenciados pela interação lâminas de irrigação x adubação azotada. Houve efeito linear do $\mathrm{N}$ sobre os teores de PB. Os teores de fibra em detergente ácido (FDA) apresentaram influência negativa da maior lâmina de irrigação e foram reduzidos pela adubação azotada. A irrigação de 50\% da ECA, associada à aplicação de $800 \mathrm{~kg}$ de N/ha/ano, apresentou os melhores resultados, considerando-se a produtividade, composição bromatológica e economia de água.

Palavras-chave: fibra em detergente ácido, fibra em detergente neutro, proteína bruta, tanque classe " $\mathrm{A}$ ".

\begin{abstract}
A bstract
The effects of different irrigation levels and doses of nitrogen $(\mathrm{N})$ on yield, nitrogen use efficiency (NUE) and chemical composition of Mombasa grass (Panicum maximum) were evaluated. The experimental design was randomized blocks in a $2 \times 4$ factorial, with three replicates, two water levels (50\% and $80 \%$ of Class A pan evaporation, ECA) and four levels of $\mathrm{N}(200,400,600$ and $800 \mathrm{~kg} / \mathrm{ha} /$ year). The water depth applied showed similar behaviors regarding NUE, total dry matter yield (TDMY), leaves (DMYL) and stems (DMYS), and levels of neutral detergent fiber (NDF). The nitrogen fertilization influenced positively TDMY, DMYL and DMYS, however, decreased NUE. Crude protein (CP) of the leaves and stems were influenced by the interaction of blades irrigation $\mathrm{x}$ nitrogen fertilization. There was a linear effect of $\mathrm{N}$ on the PB. The levels of acid detergent fiber (ADF) had negative influence of greater water depth. Concentrations of ADF were reduced by nitrogen fertilization. Irrigation of 50\% of ECA, associated with application of $800 \mathrm{~kg} N / \mathrm{ha} /$ year, showed the best results, considering productivity, chemical composition and water savings.
\end{abstract}

Keywords: acid detergent fiber, class A pan, crude protein, neutral detergent fiber. 


\section{INTRODUÇÃO}

Devido à elevada produção de fitomassa, boa aceitabilidade e bom valor nutritivo, o capim-Mombaça, uma cultivar da espécie Panicum maximum, apresenta grande importância para a pecuária do Brasil (Costa et al., 2012), cujo rebanho bovino é estimado em 209 milhões de cabeças e ocupa uma área de aproximadamente 199 milhões de hectares de pastagens (Nascimento et al., 2014). As gramíneas predominantes no país são do tipo $C 4$, com características de alta eficiência fotossintética e elevadas taxas de crescimento (Mota et al., 2008).

Contudo, nas regiões tropicais, devido às condições climáticas, as plantas forrageiras apresentam acentuada estacionalidade o que se reflete na produção pecuária. Durante o período chuvoso, devido a alta disponibilidade e bom valor nutritivo, observa-se um desempenho satisfatório dos animais. Já na época de estiagem, ocorre o oposto e, como consequência, há perda de peso ou redução drástica na produção de leite. Estes efeitos são mais expressivos na região Nordeste do Brasil.

A produção sazonal de forragem é um fenômeno que ocorre na maioria das espécies tropicais, sendo determinada, principalmente, pelas limitações de luz, disponibilidade de água e temperatura. Entretanto, o norte do Piauí, região próxima da linha do Equador, apresenta menores variações de temperatura durante o ano, cuja estacionalidade é causada, principalmente, pela irregularidade da precipitação pluvial (Magalhães et al., 2012). Assim sendo, como forma de diminuir os efeitos da estacionalidade na produção de forragens e assegurar melhores índices de produtividade da pecuária, a utilização da irrigação é condição básica e imprescindível para a região. No entanto, com a utilização de irrigação de pastagens, a fim de não restringir o seu potencial de produção, são necessários outros insumos, além de água. Dentre estes, destaca-se o uso da adubação azotada, devido ao efeito positivo do azoto sobre a produtividade das gramíneas forrageiras, além de estimular o crescimento de tecidos novos, com altos teores de proteína bruta, e baixos de fibra e lignina (Euclides, 1995; Freitas et al., 2012).

Ressalta-se que as respostas das plantas forrageiras à irrigação e adubação azotada variam conforme o potencial genético das gramíneas, a frequência de corte e as condições edafoclimáticas (Sun et al., 2008; Alencar et al., 2009). Desta forma, buscou-se com este estudo avaliar efeitos de diferentes lâminas de irrigação e doses de azoto na produtividade, eficiência de uso do azoto e a composição bromatológica do capim Panicum maximum cv. Mombaça nas condições ecológicas de Parnaíba, Piauí, Brasil.

\section{MATERIAL E MÉTODOS}

O trabalho foi conduzido na área experimental da Embrapa Meio-Norte, em Parnaíba, Piauí, durante o período de agosto a dezembro de 2007. O clima da região, de acordo com a classificação climática de Thornthwaite e Mather, é C1dA'a', caracterizado como subúmido seco, megatérmico, com pequeno excedente hídrico e uma concentração de $29,7 \%$ da evapotranspiração potencial no trimestre outubro, novembro e dezembro. Apresenta ventos moderados e umidade relativa do ar de moderada a alta. A precipitação anual média é de 1077 mm e o período chuvoso se concentra nos meses de janeiro a junho (Bastos et al., 2008).

O solo da área experimental foi classificado como Latossolo Amarelo distrófico, textura média, fase caatinga litorânea de relevo plano e suave ondulado (Melo et al., 2004), e no início do experimento apresentou as seguintes características químicas: $\mathrm{MO}=13,47 \mathrm{~g} / \mathrm{kg} ; \mathrm{pH}\left(\mathrm{H}_{2} \mathrm{O}\right)=5,84 ; \mathrm{P}=10,03 \mathrm{mg} /$ $\mathrm{dm}^{3} ; \mathrm{K}=0,08 \mathrm{cmolc} / \mathrm{dm}^{3} ; \mathrm{Ca}=1,74 \mathrm{cmolc} / \mathrm{dm}^{3} ; \mathrm{Mg}$ $=0,84 \mathrm{cmolc} / \mathrm{dm}^{3} ; \mathrm{Na}=0,08 \mathrm{cmolc} / \mathrm{dm}^{3} ; \mathrm{Al}=0,01$ cmolc $/ \mathrm{dm}^{3} ; \mathrm{H}+\mathrm{Al}=2,01 \mathrm{cmolc} / \mathrm{dm}^{3} ; \mathrm{S}=2,74 \mathrm{cmolc} /$ $\mathrm{dm}^{3} ; \mathrm{CTC}=4,75 \mathrm{cmolc} / \mathrm{dm}^{3} ; \mathrm{V}=57,84 \%$; e percentagem de saturação por alumínio, $m=0,26 \%$.

O capim Panicum maximum cv. Mombaça foi implantado no início do período chuvoso de 2005, aplicando o equivalente a $50 \mathrm{~kg} / \mathrm{ha}$ de $\mathrm{P}_{2} \mathrm{O}_{5}$, na forma de superfosfato triplo, $40 \mathrm{~kg} /$ ha de $\mathrm{K}_{2} \mathrm{O}$, na forma de cloreto de potássio em fundação e $45 \mathrm{~kg} /$ ha de azoto na forma de ureia, parcelados em duas aplicações, uma por ocasião do plantio e outra 30 dias após.

Em agosto de 2007 foi iniciada a pesquisa. Os tratamentos consistiram na aplicação de duas lâminas de irrigação (sendo uma lâmina equivalente à reposição de $50 \%$ e outra de $80 \%$ da evaporação do Tanque Classe "A" - ECA) e quatro doses de azoto (equivalentes a 200, 400, 600 e $800 \mathrm{~kg}$ de N/(ha.ano)), num delineamento em blocos casualizados, em esquema fatorial $2 \times 4$, com três repetições. As parcelas experimentais mediam $3 \mathrm{~m} \times 8 \mathrm{~m}$, definindo-se 
uma área central de $2 \mathrm{~m} \times 7 \mathrm{~m}$, como área útil para coleta de dados, sendo realizados um corte de uniformização (agosto) e quatro cortes para coleta de dados a cada 30 dias e a $20 \mathrm{~cm}$ do solo.

A adubação azotada, na forma de ureia, foi aplicada a lanço (após cada corte) e de acordo com as quantidades estabelecidas nos tratamentos $(16,7$; 33,$3 ; 50,0$ e 66,7 kg/mês), respectivamente. Durante o período experimental foram aplicados o total de 66,$8 ; 133,2 ; 200,0$ e $266,8 \mathrm{~kg}$ de N/ha. No manejo da irrigação adotou-se um turno de rega de três dias. Foi utilizado um sistema de aspersão convencional fixo, de baixa pressão e vazão. O espaçamento entre linhas laterais e entre aspersores foi de $12 \mathrm{~m} \times 12$ m. Os valores das lâminas totais de irrigação aplicadas nos tratamentos dos níveis de irrigação (50 e $80 \%$ da evaporação do Tanque Classe " $\mathrm{A}$ "), foram de 471,99 mm e 755,18 mm, respectivamente.

Em cada corte do capim-Mombaça foram coletadas amostras, que depois de separadas em folha (lâmina foliar) e colmo (colmo+bainha) foram pesadas em balança eletrônica. Em seguida, foram submetidas à pré-secagem em estufa com circulação forçada de ar, a $65^{\circ} \mathrm{C}$, até peso constante, para estimativa da relação folha/colmo, da produtividade de matéria seca (MS) e para as análises químico-bromatológicas. Os teores de proteína bruta (PB), fibra em detergente neutro (FDN) e ácido (FDA), foram determinados segundo metodologias descritas em Silva e Queiroz (2002), em biomassa pré-seca moída em peneira de $1 \mathrm{~mm}$. A digestão para obtenção da FDN e FDA foi realizada em aparelho de digestão de fibra (modelo Tecnal TE-149, similar ao Ankon).

A composição bromatológica foi obtida através da média de quatro cortes, e para a produtividade de MS total, produtividade de folhas, produtividade de colmos e a eficiência do uso de azoto, foram utilizados os valores da soma dos quatro cortes. Os dados foram submetidos à análise de variância para observação da existência ou não de interação adubação azotada x lâminas de irrigação, e as médias foram comparadas pelo teste de Tukey, ao nível de $5 \%$ de probabilidade. As equações de regressão foram obtidas isolando-se cada lâmina de irrigação em função das doses de azoto. Os dados amostrados foram analisados utilizando-se o software estatístico Assistat (Silva e Azevedo, 2002).

\section{RESULTADOS E DISCUSSÃO}

Não foi observada interação entre lâminas de irrigação e adubação azotada $(\mathrm{P}>0,05)$ sobre a produtividade de matéria seca total (PMST). Também não ocorreram efeitos significativos na produtividade de matéria seca de folhas (PMSF) e colmos (PMSC) (Quadro 1). Neste experimento era esperada uma resposta positiva das lâminas de irrigação sobre a produtividade de MS, pois conforme Aguiar et al. (2005), na região de Uberaba, Minas Gerais, ocorreram acréscimos de 28 a $41 \%$ na produtividade de MS do capim-Tifton 85 (Cynodon spp.) irrigado durante estações de verão e outono, quando as condições de temperatura e luminosidade ambientais foram favoráveis ao crescimento das plantas. Assim, a região norte do Piauí, onde foi conduzida esta pesquisa, possui condições climáticas semelhantes em todo o ano, ou seja, a temperatura e radiação solar não são fatores limitantes, mas sim a precipitação pluvial. Nas mesmas condições ecológicas, Rodrigues et al. (2005) não observaram influência das lâminas de irrigação aplicadas na produção de MS dos capins Tifton 85, Tanzânia (P. maximum) e Pioneiro (Pennisetum purpureum). Os autores ressaltaram que nas condições de solos arenosos dos tabuleiros litorâneos, a aplicação de lâminas elevadas de irrigação pode ter induzido a perda de água por percolação profunda, não permitindo que os excedentes de umidade fossem aproveitados pelo sistema radicular das gramíneas em ganhos de produtividade de MS, o que pode explicar a inexistência de diferenças significativas entre os tratamentos de irrigação utilizados. Vale salientar que, segundo Melo et al. (2004), fisicamente, o solo dos tabuleiros litorâneos do Piauí apresenta, em média, $85,63 \%$ de areia, 5,35\% de limo e 9,03\% de argila até 1,2 $\mathrm{m}$ de profundidade, além de baixa capacidade de retenção de água, com reflexos negativos na produção de matéria seca.

Os dados de produtividade de matéria seca ajustaram-se às equações de regressão lineares $(p<0,05)$ nas duas lâminas testadas em função das doses de azoto (Quadro 1). Tais equações evidenciam que a adubação azotada, independentemente da lâmina de irrigação, tende a promover o crescimento das plantas, aumentando a área fotossintética e, consequentemente, implicando maiores produções de MS. Estes resultados são concordantes com as afirmações de Novo e Camargo (2002), para os quais, as pastagens tropicais podem responder linearmente à adubação azotada até o nível de $800 \mathrm{~kg} /$ 
Quadro 1 - Produtividade de matéria seca total (PMST), de folhas (PMSF) e colmos (PMSC) do capim Panicum maximum cv. Mombaça, sob efeito de irrigação e adubação azotada (N)

\begin{tabular}{|c|c|c|c|c|c|c|c|}
\hline \multirow{3}{*}{$\begin{array}{c}\text { Lâminas } \\
\text { de } \\
\text { irrigação }\end{array}$} & \multicolumn{4}{|c|}{ Doses de N (kg/(ha.ano)) } & \multirow{3}{*}{ Médias } & \multirow{3}{*}{ Equação de regressão } & \multirow{3}{*}{$\mathrm{R}^{2}$} \\
\hline & 200 & 400 & 600 & 800 & & & \\
\hline & \multicolumn{4}{|c|}{$\operatorname{PMST}(\mathrm{t} / \mathrm{ha})$} & & & \\
\hline $50 \%$ de ECA & 8,09 & 11,01 & 13,25 & 16,68 & $12,26^{\mathrm{A}}$ & $\hat{y}=5,25109+0,16828 \mathrm{~N}$ & 0,99 \\
\hline $80 \%$ de ECA & 8,52 & 10,94 & 14,22 & 16,98 & $12,66^{\mathrm{A}}$ & $\hat{y}=5,49884+0,17213 N$ & 0,99 \\
\hline \multirow[t]{2}{*}{ CV (\%) } & 9,62 & & & & & & \\
\hline & \multicolumn{4}{|c|}{ PMSF (t/ha) } & & & \\
\hline $50 \%$ de ECA & 6,11 & 8,43 & 9,63 & 12,37 & $9,13^{\mathrm{A}}$ & $\hat{\mathrm{y}}=4,13361+0,12017 \mathrm{~N}$ & 0,99 \\
\hline $80 \%$ de ECA & 6,36 & 8,60 & 11,55 & 13,15 & $9,91^{\mathrm{A}}$ & $\hat{y}=4,08046+0,14014 \mathrm{~N}$ & 0,99 \\
\hline \multirow[t]{2}{*}{ CV $(\%)$} & 12,32 & & & & & & \\
\hline & \multicolumn{4}{|c|}{ PMSC (t/ha) } & & & \\
\hline $50 \%$ de ECA & 1,25 & 1,63 & 2,34 & 3,03 & $2,06^{\mathrm{A}}$ & $\hat{\mathrm{y}}=0,54527+0,03650 \mathrm{~N}$ & 0,98 \\
\hline $80 \%$ de ECA & 1,20 & 1,36 & 1,77 & 2,85 & $1,80^{\mathrm{A}}$ & $\hat{y}=0,45822+0,03222 \mathrm{~N}$ & 0,86 \\
\hline $\mathrm{CV}(\%)$ & 17,24 & & & & & & \\
\hline
\end{tabular}

ha de $\mathrm{N}$, podendo variar de acordo com o potencial genético das diferentes espécies, com a frequência de cortes e com as condições climáticas.

As PMSF e PMSC representaram em média 76,3 e $15,2 \%$ da PMST, respectivamente. Este resultado é bastante promissor em termos de qualidade da forragem disponível visto que os animais pastejam preferencialmente as folhas e, é nessa parte da planta onde se encontram os nutrientes mais prontamente disponíveis. Pastos com elevadas produções de matéria seca com baixo conteúdo de colmos e altas proporções de folhas são desejáveis. A alta participação de folhas pode ser explicada pela altura de corte de $20 \mathrm{~cm}$ utilizada no experimento. conforme observaram Dias Filho et al. (1992), quando trabalharam com P. maximum cv. Tobiatã na presença de estresse hídrico.

As análises de regressão, dentro das lâminas aplicadas, revelaram redução linear em função das doses de azoto. Possivelmente este fato tenha ocorrido em função das perdas de N, principalmente por lixiviação e volatilização, acarretando em redução das EUN. Vale ressaltar que os valores encontrados para EUN no menor nível de adubação foram superiores aos indicados por Gomide (1993). Fagundes et al. (2005) encontraram em B. decumbens, 57, 49, 36 e 31 de EUN, para 75, 150, 225 e $300 \mathrm{~kg}$ de N/ ha, respectivamente. Neste experimento, indepen-

Quadro 2 - Eficiência de uso do azoto (EUN) do capim Panicum maximum cv. Mombaça, sob efeito de irrigação e adubação azotada $(\mathrm{N})$

\begin{tabular}{|c|c|c|c|c|c|c|c|}
\hline \multirow{3}{*}{$\begin{array}{l}\text { Lâminas } \\
\text { de } \\
\text { irrigação }\end{array}$} & \multicolumn{4}{|c|}{ Doses de N (kg/(ha.ano)) } & \multirow{3}{*}{ Médias } & \multirow{3}{*}{ Equação de regressão } & \multirow{3}{*}{$\mathrm{R}^{2}$} \\
\hline & 200 & 400 & 600 & 800 & & & \\
\hline & \multicolumn{4}{|c|}{ EUN (kg de MS/kg de N) } & & & \\
\hline $50 \%$ de ECA & 121,54 & 82,66 & 66,25 & 62,62 & $83,27^{\mathrm{A}}$ & $\hat{y}=131,53-0,2895 N$ & 0,85 \\
\hline $80 \%$ de ECA & 127,99 & 82,18 & 71,10 & 63,74 & $86,25^{\mathrm{A}}$ & $\hat{y}=137,18-0,3055 N$ & 0,83 \\
\hline $\mathrm{CV}(\%)$ & & & & & & & \\
\hline
\end{tabular}

ECA = Evaporação do Tanque Classe A; Médias seguidas de mesma letra, nas colunas, não diferem entre si pelo teste de Tukey a 5\%.

Com relação à eficiência de uso do azoto (EUN), embora não tenha sido observados efeitos significativos $(p>0,05)$ entre as lâminas de irrigação (Quadro 2), verificou-se que, a menor lâmina foi 3,57\% menos eficiente que a maior lâmina de irrigação testada, revelando que nesta variável houve pouca influência da disponibilidade de água no solo, dente das lâminas de irrigação, a melhor EUN foi obtida na dose de $200 \mathrm{~kg}$ de N/(ha.ano).

Houve interação significativa $(\mathrm{P}<0,05)$ entre lâminas de irrigação e doses de azoto aplicadas para os teores de proteína (PB) nas folhas e colmos (Quadro 3). Nas folhas, os maiores teores de PB foram 
Quadro 3 - Teores de proteína bruta (PB) em folhas e colmos do capim Panicum maximum cv. Mombaça, sob efeito de irrigação e adubação azotada $(\mathrm{N})$

\begin{tabular}{|c|c|c|c|c|c|c|}
\hline Lâminas & & oses de & g/(ha.an & & \multirow{3}{*}{ Equação de regressão } & \multirow{3}{*}{$\mathrm{R}^{2}$} \\
\hline de & 200 & 400 & 600 & 800 & & \\
\hline irrigação & \multicolumn{4}{|c|}{ Folhas (\% de PB) } & & \\
\hline $50 \%$ de ECA & $7,66^{\mathrm{Ad}}$ & $8,69^{\mathrm{Ac}}$ & $10,27^{\mathrm{Ab}}$ & $12,80^{\mathrm{Aa}}$ & $\hat{\mathrm{y}}=7,30560+0,255 \mathrm{~N}$ & 0,96 \\
\hline $80 \%$ de ECA & $7,92^{\mathrm{Ab}}$ & $7,85^{\mathrm{Bb}}$ & $8,35^{\mathrm{Bb}}$ & $9,87^{\mathrm{Ba}}$ & $\hat{y}=7,5451+0,00953 N$ & 0,75 \\
\hline \multirow[t]{2}{*}{ CV (\%) } & 6,55 & & & & & \\
\hline & \multicolumn{4}{|c|}{ Colmos $(\%$ de $\mathrm{PB})$} & & \\
\hline $50 \%$ de ECA & $4,08^{\mathrm{Ab}}$ & $5,30^{\mathrm{Aa}}$ & $6,07^{\mathrm{Aa}}$ & $6,02^{\mathrm{Aa}}$ & $\begin{array}{c}\hat{\mathrm{y}}=2,13110+0,13507 \mathrm{~N}- \\
0,001146 \mathrm{~N}^{2}\end{array}$ & 0,99 \\
\hline $80 \%$ de ECA & $5,19^{\mathrm{Aab}}$ & $4,78^{\mathrm{Ab}}$ & $4,99^{\mathrm{Bab}}$ & $5,61^{\mathrm{Aa}}$ & $\hat{\mathrm{y}}=$ Sem ajuste & - \\
\hline CV $(\%)$ & 3,25 & & & & & \\
\hline
\end{tabular}

ECA = Evaporação do Tanque Classe A; Médias seguidas de mesma letra não diferem entre si pelo teste Tukey a 5\% de probabilidade, respectivamente, minúsculas nas linhas e maiúsculas nas colunas.

observados com aplicação de 800 kg/ha/ano na lâmina de $50 \%$, evidenciando que a redução do volume de água aplicada promoveu atraso no crescimento e na maturidade da planta, diminuindo o fator de diluição do azoto e, consequentemente, melhorando o valor nutritivo do capim-Mombaça. Estes aspectos ficam evidentes quando no presente trabalho se compara o teor médio de PB registrado na lâmina de irrigação de 50\% de ECA com o observado na lâmina de irrigação de $80 \%$ de ECA. Mota et al. (2011) também registraram redução dos teores médios de proteína bruta do capim-Elefante (Pennisetum purpureum), com o incremento das lâminas de irrigação (zero a $120 \%$ da evapotranspiração de referência).

Dentro das lâminas de irrigação, houve efeito linear da adubação azotada sob os teores de proteína bruta das folhas, e quadrático na fração colmos, na lâmina de irrigação de 50\%, em que a dose de 706,8 kg de N/ha/ano proporcionou o maior valor de PB (Quadro 3). Nas mesmas condições ecológicas, Rodrigues et al. (2010) também evidenciaram efeito linear da adubação azotada sobre a \% de PB do Tifton 85 ( $\hat{y}=9,17+0,0188$ N). Já Sousa et al. (2010) encontraram respostas quadráticas da adubação azotada (zero a $300 \mathrm{~kg}$ de N/ha) sobre os teores de PB do capim-Tanzânia $\left(\hat{y}=8,56472+0,0002 \mathrm{~N}+0,0000366667 \mathrm{~N}^{2}\right)$. Isso pode ter ocorrido em decorrência do comportamento do azoto nas plantas, que segundo Raij (1991), após sua absorção e redução para forma amoniacal e, combinado nas cadeias orgânicas se transforma em ácido glutâmico, o qual é precursor de diferentes aminoácidos, dos quais cerca de vinte são usados na formação de proteínas.

Em geral, os teores de proteína observados neste trabalho são próximos aos descritos por Euclides
(1995), quando comparou o efeito do período chuvoso x período seco sobre os teores de PB de Brachiaria brizantha cv. Marandu, cujas médias de PB foram, $11,1 \%$ (folha) e $6,0 \%$ (colmo), 8,1\% (folha) e 3,8\% (col$\mathrm{mo})$, respectivamente, para o período chuvoso e período seco. Ademais, neste experimento, apenas os teores de PB observados nos colmos não atingiram o valor mínimo de $7 \%$, o que pode reduzir a atividade microbiana do rúmen (Minson, 1984).

Não houve efeitos significativos $(p>0,05)$ entre as lâminas de irrigação sobre os teores de FDN (Quadro 4). Palieraqui et al. (2006), Cunha et al. (2007), Vitor et al. (2009) também não encontram influências de lâminas de irrigação sobre os teores de FDN dos capins Mombaça, Tanzânia e elefante, respectivamente.

$\mathrm{O}$ aumento das doses de $\mathrm{N}$ culminou em maiores índices de FDN, fato observado nas folhas sob efeito da lâmina de irrigação de $80 \%$ de ECA. Na fração colmos não houve influência $(P>0,05)$ de nenhum dos tratamentos testados na FDN (Quadro 4). Tendências de elevação dos valores de FDN com o aumento das doses de $\mathrm{N}$ foram encontradas por Dias et al. (2000) em que os autores afirmaram que doses mais elevadas de azoto aplicadas em determinada época, dependendo das condições ambientais, podem alterar o teor de FDN das forrageiras para maiores ou menores valores. $\mathrm{O}$ aumento das doses de azoto e consequente aumento de massa verde implica a deposição de compostos na parede celular para manter a sustentação da planta e, consequentemente, maiores valores de fibra como observado no presente trabalho. 
Quadro 4 - Teores de fibra em detergente neutro (FDN) em folhas e colmos do capim Panicum maximum cv. Mombaça, sob efeito de irrigação e adubação azotada (N)

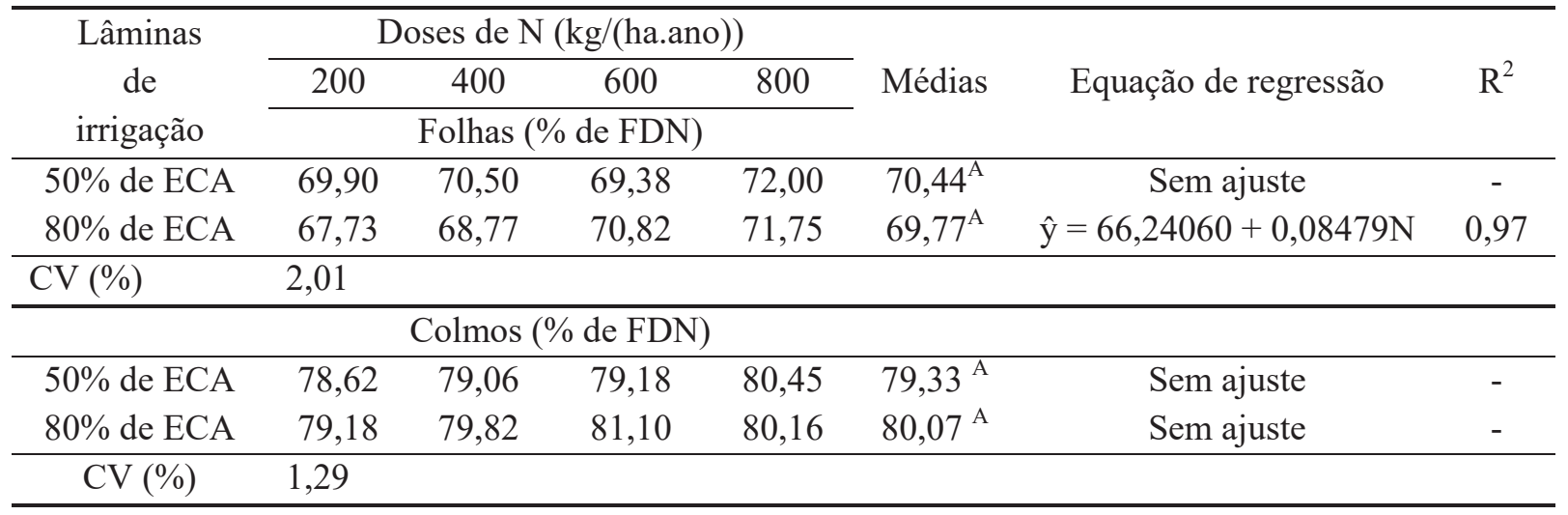

ECA = Evaporação do Tanque Classe A; Médias seguidas de mesma letra, nas colunas, não diferem entre si pelo teste de Tukey a 5\%.

Euclides (1995), estudando diversas cultivares de Pancium maximum, concluiu que valores de FDN inferiores a $55 \%$ são raros. Valores superiores a $65 \%$ são comuns em tecidos novos e teores entre 75 e $80 \%$ são encontrados em materiais de maturidade avançada. A FDN apresenta uma relação inversa com o consumo voluntário do pasto, ou seja, menores valores de FDN implicam maior consumo da forrageira.

Houve influência das lâminas de irrigação $(\mathrm{P}<0,05)$ nos teores de fibra em detergente ácido (FDA) das folhas (Quadro 5), em que a lâmina de irrigação de $50 \%$ de ECA apresentou efeito quadrático, com a dose de $482,4 \mathrm{~kg}$ de $\mathrm{N} /($ ha.ano) proporcionando menores valores.

Para a fração colmos houve influência das lâminas de irrigação $(\mathrm{P}<0,05)$. Na lâmina de $80 \%$ (Quadro 5) observou-se um efeito linear positivo das doses de azoto, culminando em elevação dos teores de FDA. Os dados obtidos neste trabalho corroboram os de
Cunha et al. (2007), que observaram uma tendência de quanto maior a lâmina de irrigação aplicada maiores os teores de FDA.

A FDA varia com a idade da planta e com o seu estresse em função da precipitação e da umidade do solo. Os resultados obtidos por Freitas et al. (2007) sugerem que o intervalo de cortes utilizado na pesquisa, de 28 dias, não permitiu um aumento na concentração de fibra. O teor de fibra representado pela FDA constitui um importante parâmetro para comparar efeitos de doses crescentes de fertilizantes, no caso de azoto. Nussio et al. (1998), destacaram que forragens com valores de FDA de cerca de $40 \%$, ou mais, apresentam baixo consumo e menor digestibilidade.

Os teores de FDA nos colmos estão de acordo com os de Rego et al. (2003), que constataram que, independentemente da altura de manejo do pasto, os teores de FDA dos colmos foram sempre superiores

Quadro 5 - Teores de fibra em detergente ácido (FDA) em folhas e colmos do capim Panicum maximum cv. Mombaça, sob efeito de irrigação e adubação $(\mathrm{N})$

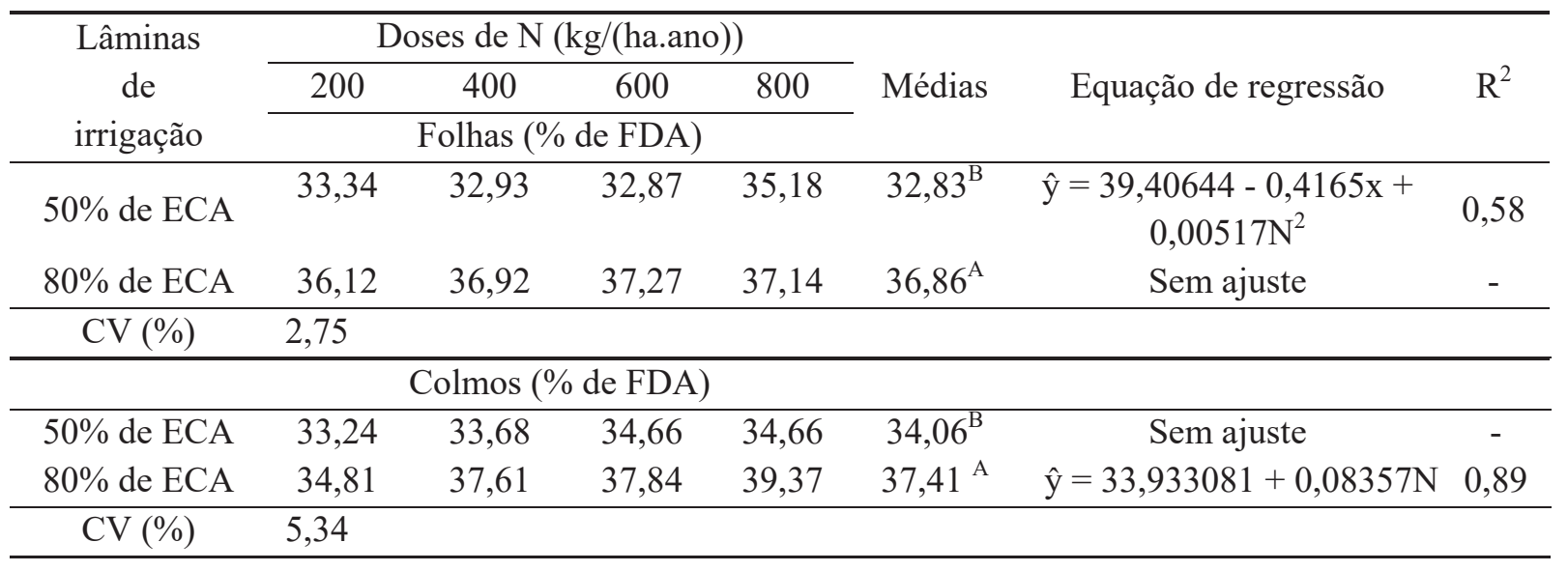

ECA = Evaporação do Tanque Classe A; Médias seguidas de mesma letra, nas colunas, não diferem entre si pelo teste de Tukey a 5\%. 
aos das folhas. As diferenças encontradas nas variáveis aqui estudadas são condizentes com o que foi destacado por Pieterse et al. (1997) estudando 4 variedades de $P$. maximum, no qual observaram que dentro de uma mesma espécie, mas em diferentes cultivares, há uma vasta diferença nos teores de MS, PB, FDN e FDA.

\section{CONCLUSÕES}

Para condições ecológicas dos Tabuleiros Costeiros do Piauí, a reposição de 50\% de ECA, associada à aplicação de até $800 \mathrm{~kg}$ de N/(ha.ano), apresentou os melhores resultados, considerando-se a produtividade de MS, composição bromatológica e a possibilidade de economia de água e adubo, com a consequente redução nos custos de produção do capim-Mombaça.

\section{REFERENCIAS BIBLIOGRÁFICAS}

Aguiar, A.P.A.; Drumond, L.C.D.; Fernandes, A.L.T.; Felipini, T.M.; Monteiro, S.; Pontes, P.O. e Silva, A.M. (2005) - Efeito da irrigação sobre a massa de forragem e a densidade da forragem em pastagens intensivas de capim Tifton 85 . FAZU em Revista, vol. 2, n. 1, p. 14-20.

Alencar, C.A.B.; Oliveira, R.A. de; Coser, A. C.; Martins, C. E.; Cunha, F. F. da e Figueiredo, J.L.A. (2009) - Produção de capins cultivados sob pastejo em diferentes lâminas de irrigação e estações anuais. Revista Brasileira de Engenharia Agrícola e Ambiental, vol. 13, n. 6, p. 680-686.

Bastos, E.A.; Andrade Júnior, A.S. de e Rodrigues, B.H.N. (2008) - Boletim agrometeorológico de 2007 para o Município de Parnaíba, Piauí. Teresina, Embrapa Meio-Norte. 37 p.

Costa, N. de L.; Magalhães, J.A.; Carneiro, M.S. de S.; Xavier, T.F.X.; Nascimento, L.E. da S. e Furtado, F.M.V. (2012) - Produção e composição química de Panicum maximum cv. Mombaça sob diferentes níveis de potássio. Pubvet (Londrina), vol. 6, p. 1388.

Cunha, F.F. da; Soares, A.A.; Pereira, O.G.; Mantovani, E.C.; Sediyama, G.C. e Abreu, F.V. de S. (2007) - Composição bromatológica e digestibilidade "in vitro" da matéria seca do capim-Tanzânia irrigado. Bioscience Journal (UFU), vol. 23, n. 2, p. 25-33.

Dias, P.F.; Rocha, G.P.; Rocha Filho, R.R.; Leal, M.A.A.; Almeida, D.L. e Souto, S.M. (2000)
- Produção e valor nutritivo de gramíneas forrageiras tropicais, avaliadas no período das águas, sob diferentes doses de nitrogênio. Ciência e Agrotecnologia, vol. 24, n. 1, p. 260-271.

Dias Filho, M.B.; Corsi, M. e Cusato, S. (1992) Concentration uptake and use efficiency of $\mathrm{N}$, $\mathrm{P}$ and $\mathrm{K}$ in Panicum maximum Jacq. cv. Tobiatã under water Stress. Pesquisa Agropecuária Brasileira, vol. 27, n. 3, p. 381-387.

Euclides, V.P.B. (1995) - Valor alimentício de espécies forrageiras do gênero Panicum. In: $12^{\underline{0}}$ Simpósio Sobre Manejo da Pastagem. Piracicaba, Brasil. Piracicaba: FEALQ, p. 245-273.

Fagundes, J.L.; Fonseca, D.M.; Gomide, J.A. Gomide, J.A.; Nascimento Júnior, D. do; Vitor, C.M.T.; Morais, R.V.; Mistura, C.; Reis, G.C. e Mastuscello, J.A. (2005) - Acúmulo de forragem em pastos de Brachiaria decumbens adubados com nitrogênio. Pesquisa Agropecuária. Brasileira, vol. 40, n. 4, p. 397-403. http://dx.doi.org/10.1590/S0100-204X2005000400012

Freitas, F.P. de; Fonseca, D.M. da; Braz, T.G. dos S.; Martuscello, J.A. e Santos, M.E.R. (2012) Forage yield and nutritive value of Tanzania grass under nitrogen supplies and plant densities. Revista Brasileira de Zootecnia, vol. 41, p. 864-872. http://dx.doi.org/10.1590/S1516-35982012000400006

Freitas, K.R.; Rosa, B. e Ruggiero, J.A. (2007) Avaliação da composição químico-bromatológica do capim-Mombaça (Panicum maximum Jacq.) submetido a diferentes doses de nitrogênio. Bioscience Journal, vol. 23, n. 3, p. 1-10.

Gomide, J.A. (1993) - Produção de leite em regime de pasto. Revista da Sociedade Brasileira de Zootecnia, vol. 22, n. 4, p. 591-613.

Magalhães, J.A.; Carneiro, M.S.S.; Andrade, A.C. ; Pereira, E.S.; Souto, J.S. ; Pinto, M.S. de C.; Rodrigues, B.H.N.; Costa, N. de L. e Mochel Filho, W.J.E. (2012) - Eficiência do nitrogênio, produtividade e composição do capimandropogon sob irrigação e adubação. Archivos de Zootecnia, vol. 61, p. 577-588.

http://dx.doi.org/10.4321/S0004-05922012000400010

Melo, F. de B.; Cavalcante, A.C.; Andrade Júnior, A.S. e Bastos, E.A. (2004) - Levantamento detalhado dos solos da área da Embrapa Meio-Norte/UEP de Parnaíba. Teresina: Embrapa Meio-Norte. 26 p. (Documentos, 89).

Minson, D.J. (1984) - Effects of chemical and physical composition of herbage eaten upon intake. In: Hacker, J.B. (Ed.). Nutritional limits to animal production from pasture. CAB. Farnham Royal. UK. pp. 167-182. 
Mota, M.F.; Vilela, D.; Santos, G.T.; Elyas, A.C.W.; Lopes, F.C.F.; Verneque, R.S. e Pinto Neto, A. (2008) - Desempenho produtivo e composição do leite de vacas da raça holandesa no final da lactação, manejadas em pastagem e suplementadas com diferentes níveis de concentrado. Revista Brasileira de Ciência Veterinária, vol. 15, n. 2, p. 82-87.

Mota, V.J.G.; Rocha Júnior, V.R.; Reis, S.T.; Sales, E.C.J.; Oliveira, F.G.; Gomes, V.M.; Martins, C.E. e Cóser, A.C. (2011) - Lâminas de irrigação e doses de nitrogênio em pastagem de capimelefante no período chuvoso no norte de Minas Gerais. Revista Brasileira de Saúde e Produção Animal, vol. 12, n. 4, p. 908-922.

Nascimento, L.E. da S.; Rocha, J.A.; Magalhães, J.A.; Costa, N. de L. ; Nascimento, T.S. e Townsend, C.R. (2014) - Subsídios técnicos para gestão ambiental em sistemas silvipastoris. Pubvet (Londrina), vol. 8, n. 6, p. 1686.

Novo, A.L.M. e Camargo, A.C. de. (2002) - Manejo intensivo de pastagens. In: $3^{\circ}$ Curso à Distancia em Bovinocultura Leiteira: manejo de pastagens. Instituto Fernando Costa. São Paulo, Brasil.

Nussio, L.G., Manzano, R.P. e Pedreira, C.G.S. (1998) - Valor alimentício em plantas do gênero Cynodon. In: 15ํ Simpósio Sobre Manejo da Pastagem. Piracicaba, Brasil. Piracicaba: FEALQ, p. 203-242.

Palieraqui, J.G.B.; Fontes, C.A. de A.; Ribeiro, E.G.; Cóser, A.C. e Martins, C.E.M.; Fernandes, A.M. (2006) - Influência da irrigação sobre a disponibilidade, a composição química, a digestibilidade e o consumo dos capins Mombaça e napier. Revista Brasileira de Zootecnia, vol. 35, n. 6, p. 2381-2387.

http://dx.doi.org/10.1590/S1516-35982006000800026

Pieterse, P.A.; Rethman, N.F.G. e Van Bosch, J. (1997) - Production, water use efficiency and quality of four cultivars of Panicum maximum at different levels of nitrogen fertilization. Tropical Grassland, vol. 31, n. 2, p. 117-123.

Raij, B.V. (1991) - Fertilidade do solo e adubação. Piracicaba: Ceres, Potafo,. p.163-179.
Rego, F.C.A.; Cecato, U.; Damasceno, J.C.; Ribas, N.P.; Santos, G.T. dos ; Moreira, F.B. e Rodrigues, A.M. (2003) - Valor nutritivo do capim-Tanzania (Panicum maximum Jacq cv. Tanzania-1) manejado em alturas de pastejo. Acta Scientiarum. Animal Sciences, vol. 25, n. 2, p. 363-370.

http://dx.doi.org/10.4025/actascianimsci.v25i2.205

Rodrigues, B.H.N.; Andrade, A.C.; Magalhães, J.A. e Costa, N. de L. (2010) - Determinação do teor de proteína bruta de Panicum maximum cv. Tanzânia, sob diferentes níveis de irrigação e adubação azotada. Pubvet (Londrina), vol. 4, p. 1-8.

Rodrigues, B.H.N.; Magalhães, J.A.; Lopes, E.A. (2005) - Irrigação e adubação nitrogenada em três gramíneas forrageiras no Meio-Norte do Brasil. Revista Ciência Agronômica, vol. 36, n. 3, p. 274-278.

Silva, F.A.S. e Azevedo, C.A.V. (2002) - Versão do programa computacional Assistat para o sistema operacional Windows. Revista Brasileira de Produtos Agroindustriais, vol. 4, n. 1, p. 71-78.

Silva, D.J. e Queiroz, A.C. (2002) - Análises de alimentos: métodos químicos e biológicos. $3^{\text {a }}$ ed. Imprensa Universitária. UFV. Viçosa. 235 pp.

Sousa, R.S.; Pires, A.J.V.; Carvalho, G.G.P. de; Silva, F.F. da; Magalhães, A.F. e Veloso, C.M. (2010) - Composição química de capim-Tanzânia adubado com nitrogênio e fósforo. Revista Brasileira de Zootecnia, vol. 39, n. 6, p. 1200-1205. http://dx.doi.org/10.1590/S1516-35982010000600006

Sun, X.;Luo,N.;Longhurst,B.eLuo,J.(2008)-Fertiliser nitrogen and factors affecting pasture responses. The Open Agriculture Journal, vol. 2, p. 35-42. http://dx.doi.org/10.2174/1874331500802010035

Vítor, C.M.T.; Fonseca, D.M.; Cóser, A.C.; Martins, C.E.; Nascimento Júnior, D. e Ribeiro Júnior, J.I. (2009) - Produção de matéria seca e valor nutritivo de pastagem de capim-elefante sob irrigação e adubação nitrogenada. Revista Brasileira de Zootecnia, vol. 38, n. 3, p. 435-442. http://dx.doi.org/10.1590/S1516-35982009000300006 